\section{What about the bleeding time?}

With dozens of tests now available to detect bleeding tendencies is the old fashioned bleeding time any more than an old fashioned joke?

Despite its age (it was introduced in $1910^{2}$ ) many people believe that the bleeding time is the most reliable indicator of whether a patient's platelets work satisfactorily. ${ }^{3}$ In a recent survey of British haematologists, Poller et al found that $88.5 \%$ used the test routinely. ${ }^{4}$ The problem is standardisation. Duke's original method using an earlobe prick is particularly difficult to perform in a standard way. ${ }^{2}$ Only $17 \%$ of British haematologists still use it, though some prefer it for children. Its variability may be gauged from the fact that the upper limit of the normal range is regarded by various doctors as anything between 3 and 20 minutes and that the depth of the stab varies from 1 to $5 \mathrm{~mm}$.

The Ivy test, in which stabs or slits are made on the volar surface of the forearm while the capillary pressure is increased by a sphygmomanometer cuff set at $40 \mathrm{~mm} \mathrm{Hg}$, was introduced for standardising the bleeding time. ${ }^{5}$ Various modifications have been made to get reproducible results with a relatively narrow normal range in the hope that even mild platelet functional defects might be discovered: these include the use of a template to standardise the skin incision, ${ }^{6}$ of a standard dose of aspirin to stress the platelets, ${ }^{7}$ and of an automated device to make the incision. ${ }^{8}$

Poller et al also found considerable variation in the practice of British haematologists, with depth of incision varying from 0.5 to $5 \mathrm{~mm}$ and the frequency of blotting of the bleeding point being either every 15 seconds or every 30 seconds. ${ }^{+}$One encouraging trend towards standardisation was seen in that nearly half used the spring loaded Simplate device and of these $70 \%$ used an upper normal limit of between 8.5 and 10.5 minutes. The use of aspirin to stress the test is not popular, and some haematologists do not even take a history of drug intake.

How, then, should the bleeding time be used? Judiciously. Of prime importance when investigating a patient with a bleeding tendency is the history-which must include a drug history. Lind lists 19 drugs which have been reported as prolonging the bleeding time, and doubtless there are more. ${ }^{9}$ Secondly, no patient should have his bleeding time tested without first having had a platelet count. A count of less than $100 \times 10^{9} / 1$ will prolong the bleeding time, ${ }^{6}$ and in severe thrombocytopenia troublesome haemorrhage may occur from the incision. Thirdly, unless the aspirin stressed bleeding time is to be used, no aspirin should have been taken in the previous seven days.

Finally, unless the laboratory concerned is one with great experience, rigid attention to detail, and strict internal standardisation, the method chosen should limit the variables as much as possible. The Simplate device provides thisthough there may be legitimate worries, particularly in children, about the small scars that are left.

The bleeding time is extremely helpful in the diagnosis of von Willebrand's disease and as a screening test in a host of primary and secondary disorders of platelet function, well reviewed by Lind. ${ }^{9}$ But it must be performed and interpreted properly. Poller's paper has convinced me that for many haematologists the normal bleeding time is longer than they think.

Consultant Haematologist

T J HAMBLIN

Royal Victoria Hospital,

Bournemouth BH1 4JG
1 Gordon R. Doctor in the house. London: Michael Joseph, 1952

2 Duke WW. The relation of blood platelets to hemorrhagic disease. Description of a method for determining the bleeding time and the coagulation time. $\mathcal{F A M A}$ 1910;55:1185-92.

Levine PH. Platelet function tests: predictive values. $N$ Engl f Med 1975;292:1346-7

4 Poller L, Thomson JM, Tomenson JA. The bleeding time: current practice in the UK. Clin Lab Haematol 1984;6:369-73.

Ivy AC, Nelson D, Bucher G. The standardisation of certain factors in the cutaneous "venostasis" bleeding time technique. $\mathrm{f} \mathrm{Lab} \mathrm{Clin} \mathrm{Med} \mathrm{194v;26:1812-22.}$

6 Hanker LA, Slichter SJ. The bleeding time as a screening test for the evaluation of platelet function. N Engl f Med 1972;287:155-9.

Mielke CH. Aspirin prolongation of the template bleeding time: influence of venostasis and direction of incision. Blood 1982;60:1139-42.
d

8 Kumar R, Ansell JE, Canose KT, Deykin D. Clinical trial of a new bleeding time device. Am 7 Clin Pathol 1978;70:642-5.

Lind SE. Prolonged bleeding time. Am J Med 1984;77:305-12.

\section{Ingrowing toenails}

In an ideal health system delivery of care should be prompt, the treatment chosen effective with little prospect of recurrence, at a reasonable financial cost to the community, and with swift return of the patient to full normal activities if possible. These tests should be applicable to patients with common conditions causing a good deal of acute pain and discomfort, leading to loss of time from work or school, and affecting both the hospital and general practitioner services.

Why not, therefore, ask the patient with an ingrowing toenail how he feels about the treatment he has received? The answer is unlikely to be complimentary. It remains a condition with a high recurrence rate, often after multiple operations with much time wasted at outpatient clinics and on waiting lists. The cost to the community of this one simple condition must be astronomical.

Anyone who examines medical undergraduates looks for a simple question that will test whether they are aware of the common conditions-mundane, perhaps, but important nevertheless to the patient-which in future will fill their surgeries and keep returning if not properly managed. Do not ask them about the significance of a raised serum $\alpha$ lipoprotein concentration, but ask instead what they know about toenail problems. The sting in the tail will be whether they think about the conditions which on rare occasions masquerade as an ingrowing toenail-for example, a subungual melanoma-and whether they consider other diseases such as diabetes or peripheral vascular disease which may be missed with distressing results.

Why is the standard of treatment of ingrowing toenails so poor? One possible reason is the mistaken impression that being a simple condition it must have a quick and easy solution. That this is not the case is evident from the very high recurrence rate. The other problem is that its management falls between the two stools of general practice and hospital services. Treatment may be given by the general practitioner and in some cases a form of surgery undertaken. At the hospital end a variety of departments including accident and emergency, orthopaedic, and general surgery may have the patient sent to them, with doctors in each discipline embarking on different treatment policies.

Most of the published work on ingrowing toenails has been concerned with the description of various operative techniques and comparison of one with another, and what emerges is that the methods of management are diverse, and each has its own proponents. The differences are in fact small. What is much more important, however, is that surgeons should recognise the importance (in this as with other conditions) of their following up their patients over a long period of time to evaluate the results of treatment and to refine their technique in the light of this experience. 
The ideal setting for this approach is a special unit in which appropriate skills can be practised and taught. Some large hospital centres have established toenail clinics calling on the interrelated specialties and catering for many patients. Yet a group practice may be the best place to site a toenail clinic: costs are generally lower, and many surgeries and health centres provide a setting for close liaison with other disciplines such as district nurses and chiropody services. The patient receives his treatment sooner from the general practitioner at the time of first presentation with a shorter waiting time. Referral to hospital invariably causes delay, and the hospital visit can be a forbidding experience.

Well tested techniques can be learnt and applied by the general practitioner. Treatment has to be tailored to two main groups of patients. When the patient presents with an acutely infected ingrowing toenail simple conservative measures are very unlikely to produce a prompt response and control of infection. Avulsion of the nail is more likely to achieve this, but removal of the whole nail is not necessary; a sliver of the nail edge may be taken off, as suggested by Fowler, ${ }^{1}$ and this can be done without local anaesthetic with minimal discomfort to the patient. ${ }^{2}$ Another approach with equally reliable results is the gutter technique, carefully assessed and described by Wallace et $a l .^{3}$

In the case of the recurrent or chronic ingrowing toenail some form of ablation of the germinal matrix is needed, and there seems very little to choose between segmental excision ${ }^{4}$ and phenol ablation ${ }^{5}$ in terms of results.

The choice of technique should be left to individual preference. Neither is "easier" and both require close attention to detail, not only of operative techniques but also of postoperative dressings and careful follow up in the short and long term.

Total nail bed ablation should be reserved for the uncommon case where the whole nail is embedded and in onychogryphosis.

\section{S S MILLER}

Consultant Surgeon,

Aberdeen Royal Infirmary,

Aberdeen AB9 2ZB

1 Fowler AW. Ingrowing toenails. BrMed f 1976;ii:815-6.

2 Cameron PF. Ingrowing toenails-an evaluation of two treatments. Br Med f 1981;283:821-2.

3 Wallace WA, Milne DD, Andrew TT. Gutter treatment for ingrowing toenails. Br Med $\mathcal{f}$ 1979;ii:168-71.

4 Fowler AW. Excision of the germinal matrix. A unified treatment for embedded toenail and onychogryphosis. Br J Surg 1958;45:382-7.

5 Ross WR. Treatment of the ingrowing toenail. Surg Clin North Am 1969;49:1499-504.

\section{Treating hay fever}

An increased understanding of the pathophysiology of pollenosis (see leading article last week, p 1) enables treatment to be based on rational grounds. $H_{1}$ antihistamines have long been known to be an effective treatment of hay fever. Two new antihistamines, terfenadine and astemizole, have recently become available which are free of the sedative and anticholinergic side effects associated with the older preparations. ${ }^{12}$ Though both of these drugs are potent $\mathrm{H}_{1}$ receptor antagonists, they differ in their pharmacokinetics. Terfenadine has a rapid onset and offset of action and is therefore ideally suited for intermittent symptomatic treatment. If it is to be used prophylactically then $60 \mathrm{mg}$ twice daily is recommended. ${ }^{3}$ By contrast, astemizole has a slower onset of action and a prolonged half life of up to 19 days on account of its slow release from hepatic lysozomes and its almost irreversible binding to $\mathrm{H}_{1}$ receptors. ${ }^{4}$ Though the delayed onset of maximal action of astemizole may be overcome to some extent by giving a loading dose, this drug is better for maintenance than occasional use.

Many patients gain considerable benefit from the use of $\mathrm{H}_{1}$ antagonists, but their main effects are on sneezing, rhinorrhoea, and conjunctivitis with little impact on nasal obstruction. Should this latter symptom present a problem then the additional use of an inhaled steroid should be considered. ${ }^{6}$ It is likely that the anti-inflammatory effect of nasal steroids is manifested through their inhibitory activity on the colonisation of the mucosa with mast cells, ${ }^{7}$ the generation of newly formed mediators, ${ }^{8}$ and inhibition of leucocyte chemotaxis, thereby limiting the inflammatory cell component of the disease. ${ }^{9}$ Mast cell stabilising drugs such as sodium cromoglycate, ketotifen, and nedocromil may also be helpful as prophylactic agents, but since these drugs have minimal effects on basophil degranulation they provide only partial relief of symptoms. ${ }^{10}$ Immunotherapy with specific and purified allergen extracts is widely advocated in the prophylactic treatment of hay fever, but frequent injections are required for effective results and there is an appreciable morbidity unless they are given in controlled conditions where anaphylactic reactions may be treated swiftly. ${ }^{11}$ To overcome these systemic effects, local nasal immunotherapy has been tried. This has been successful with moderate doses of aqueous allergen extract ${ }^{12}$ but is associated with appreciable local adverse reactions. Reduction of the allergen dose to minimise the local adverse effects has unfortunately not been found to be clinically beneficial in preventing seasonal allergic nasal symptoms. ${ }^{13}$

Pollenosis affects $10-15 \%$ of the population, and, though its symptoms may often be relatively mild and temporary, they deserve the benefit of optimal treatment since they occur in summer, when examinations and outside recreational activities dominate.

STEPHEN T Holgate

Reader in medicine and honorary consultant physician

University of Southampton,

Peter H Howarth

Lecturer in medicine

Southampton General Hospital,

Southampton SO9 4XY

1 Brandon ML, Weiner M. Clinical investigation of terfenadine, a non-sedating antihistamine. Ann Allergy 1980;44:71-5.

2 Howarth PH, Emanuel MB, Holgate ST. Astemizole, a potent $\mathrm{H}_{1}$-receptor antagonist: effect in allergic rhinoconjunctivitis, on antigen and histamine induced skin weal responses and allergic rhinoconjunctivitis, on antigen and histamine ind
relationship to serum levels. Br $\mathcal{A}$ Clin Pharmacol 1984;18:1-8.

3 Anonymous. The management of hay fever [Editorial]. Drug Ther Bull 1985;23:25-7.

4 Laduron PM, Jansson PFM, Gommeren W, Leysen JE. In vitro and in vivo binding characteristics of a new long acting histamine $\mathrm{H}_{1}$-antagonist, astemizole. Mol Pharmacol 1982;21:294-300.

5 Vanden Bussche G. Astemizole: an update on clinical experience in over 2000 patients. In: Hutber G, ed. Néw developments in antihistamine therapy. Oxford: Medicine Publishing Foundation (in press)

6 Mygind N. Topical steroid treatment for allergic rhinitis and allied conditions. Clin Otolaryngol $1982 ; 1: 343-52$.

7 Otsuka H, Denburg J, Dolovich J, et al. Human nasal metachromatic cell (HNMC) heterogeneity: relation to clinical status and response to beclomethasone dipropionate. 7 Allergy Clin Immunol 1985;75(suppl): 153 .

8 Mygind N. Mediators of nasal allergy. I Allergy Clin Immunol 1982;70:149-59.

9 Okuda M. Mygind N. Pathophysiological basis for topical steroid treatment in the nose. In: Mygind N, Clark TJH, eds. Topical steroid treatment for asthma and rhinitis. London: Baillière Tindall, 1980:22-8.

10 Church MK. Biochemical basis of pulmonary and antiallergic drugs. In: Devlin JP, ed. Pulmonary and antiallergic drugs. New York: John Wiley and Sons Inc, 1985:43-121.

11 Rands DA. Anaphylactic reaction to desensitisation for allergic rhinitis and asthma. $\mathrm{Br}$ Med $\mathcal{F}$ 1980;281:854.

12 Nickelsen JA, Georgitis JW, Mueller UR, et al. Local nasal immunotherapy for ragweed-allergic rhinitis. Clin Allergy 1983;13:509-19.

13 Georgitis JW, Nickelsen JA, Wypech JI, Kane JH, Reismann RE. Local nasal immunotherapy: efficacy of low dose aqueous ragweed extract. $\mathcal{F}$ Allergy Clin Immunol 1985;75:496-500. 